\title{
Creativity and the Golden Years: Biopsychosocial and Cultural Influences for Living a Successful Life
}

\author{
Karen V. Duhamel \\ Department of Nursing, University of Hartford, United States
}

Copyright $\bigcirc 2016$ by authors, all rights reserved. Authors agree that this article remains permanently open access under the terms of the Creative Commons Attribution License 4.0 International License

\begin{abstract}
Living successfully into older adulthood is becoming the new social norm. As one ages, the older adult may experience doubt and insecurity about one's ongoing purpose in life, leading to feelings of failure and stagnation. The purpose of this paper is to explore the role of creativity as a requisite to living a successful life into older adulthood. By examining creativity from a variety of perspectives, social scientists and healthcare professionals can better understand the importance of empowering older adults to tap into their inner resources to promote creative expression leading to self-transformation and personal satisfaction. This paper will discuss the connection between creativity and successful aging by investigating biopsychosocial and cultural indicators, conceptual frameworks, and the benefits of incorporating creativity into the aging process through mind, body and spirit analysis.
\end{abstract}

Keywords Creativity, Older Adulthood, Successful Living

\section{Introduction}

\subsection{Biopsychosocial and Cultural Implications for Living a Successful Life}

As older adults become the new societal "In Crowd", creativity is being viewed by many as an essential component in the aging process. Research indicates living a creative life can lead to a more mentally and physically-fit older individual, unafraid of uncertainty and eager for success. The purpose of this paper is to explore the role of creativity from a variety of social, physiological and cultural perspectives for living a successful life into older adulthood. In researching this topic, this writer found limited scholarly sources that highlight the relationship between creativity and growing old successfully. This paper will discuss this connection by investigating biopsychosocial and cultural indicators, conceptual frameworks, and the benefits of incorporating creativity into the aging process through mind, body, and spirit analysis. By examining creativity from a variety of viewpoints, social scientists and healthcare professionals can better understand the importance of empowering older adults to tap into their inner resources and life histories to promote creative expression leading to self-transformation and personal satisfaction.

The World Health Organization [1] and the United Nations agree that 60 years or older is considered "the golden years" in most cultures and the acceptable age range for an individual to be considered of "old age". In Sub-Saharan Africa, the WHO states individuals $50+$ years or older, are deemed to be of old age due to environmental deficits that significantly reduce an individual's lifespan [1]. The U.S. Census reports that in 2000 there were 35 million people aged 65 and older with 4 million over age 85 , amounting to 12 percent of the population [2]. By 2030, almost one in five Americans will be at least 65 years old; representing 72 percent of older Americans of non-Hispanic White ethnicity, 11 percent Hispanic, 10 percent Black and 5 percent of Asian descent [2]. These socio-cultural indicators demonstrate the cultural diversity prevalent in society, with creative expression as one of many common bonds shared among cultures.

Despite cultural differences, many older adults face chronic health issues which tend to become more prominent with the advancement in years, affecting one's ability to experience personal creativity and successful aging. The Centers for Disease Control and Prevention (CDC) report that since 1910, heart disease has reigned as the leading cause of death in older adults, at $23.4 \%$ and cancer at $22.5 \%$ respectively [3]. Older adults continue to battle other chronic diseases and conditions, such as stroke, chronic lower respiratory diseases, Alzheimer's disease, diabetes, influenza, and pneumonia. Additionally, approximately $25 \%$ of older adults have some manifestation of mental illness [3]. Many seniors report an absence of social supports in their lives; thus, further contributing to a perceived lower quality of life and loss of creative independence [4]. These biopsychosocial and cultural factors are often influenced by changes in societal roles, relationships and one's living 
arrangements [5]. For some older adults', an inability to adapt to change and uncertainty in life, while maintaining a sense of control, are central to many conceptual frameworks associated with successful aging $[6,7,8]$.

\section{Conceptual Frameworks}

Bandura [8] stated, "The human mind is generative, creative, proactive, and reflective, not just reactive" (p. 4). Creative expression, according to Bandura's Social Change Theory, involves four components of self-agency (doing for oneself): intentionality (completing a pre-planned act); forethought (setting and meeting goals); self-reactiveness (self-satisfaction through personal choice) and self-reflection (personal values, meaning, and priority) [8].

Erikson [9] viewed success in older adulthood from the developmental stage of "Wisdom/Ego Integrity vs. Despair". During this phase, which typically occurs from age 65 onward, the older adult performs a self-inventory of their life, reflecting on their perceived successes and failures, and looks back with a sense of either satisfaction or disappointment. Erikson believes personal wisdom is the result of accomplishing this final developmental task [7]. Many older adults view creative endeavors in later life as positive experiences that allow for personal expression and self-transformation.

Schulz \& Heckhausen [10], in their Life-span theory of control, view one's lifetime of success, from a perspective of how much control the individual has within their environment. The fundamental assumptions of their theory are that individuals attempt to achieve positive results in their immediate surroundings through primary control, involving the selection of goals in a preferred domain (area of expertise) by compensating for a lack of skill or ability in other sectors. In the case of creative activity, Schulz \& Heckhausen [10] believe successful aging involves fostering primary control throughout one's life by reinforcing expertise in a creative skill in which the individual is proficient. Their second premise, secondary control, attempts to achieve stability directly within the individual. With selective control, the individual focuses on the investment of personal resources, such as time and creative talent required for a chosen goal. Additionally, the selected goal is considered for its value to the individual's need for accomplishment. Finding meaning and satisfaction in how productive the older adult can be within one's environment, through choice and practice in one's natural and pursued talents, contributes to the individual's sense of accomplishment and success in later life [10].

\section{Successful Aging}

Successful aging has been examined from many viewpoints. At the core of most beliefs are universal themes of personal growth, adaptation, health status, and motivation
$[11,12,13,14,15,16,17]$. Successful aging involves the individual's perceived fulfillment in adjusting to physical and cognitive changes while staying connected to others; resulting in a sense of belonging and personal achievement [16].

Featherman, Smith, and Peterson [18] consider the older adult's ability to adapt and accommodate to changes in one's mind, body, and environment as elements of successful aging. Other proponents of successful aging look at an individual's cognitive and emotional levels of functioning, while others focus on one's artistic abilities [19]. Tornstam [20] looked at successful aging from a perspective of gero-transcendence, in which the older adult is transformed through self-reflection and spiritual growth, and becomes more concerned with a broader connection and contribution to humanity.

\section{Creativity in Later Life}

Creativity in older adulthood involves adaptability, flexibility, and healthy coping strategies [21,16]. Csikszentmihalyi [22] postulates creative people demonstrate an autotelic-type personality, by which they are intrinsically-motivated (self-driven), intuitively-curious, and personally-challenged by the creative process. External rewards, such as praise and monetary gain, are remote motivators. Creativity also has been described as a culmination of cognitive and psychological assets involved in the formation of useful products [23] or as the ability to circumvent problems through divergent (imagination, innovation, intuition) and convergent thinking (analysis, synthesis, evaluation) [24]. Fisher and Specht [11] believe creativity fosters a sense of proficiency, purpose, and self-growth - characteristics essential to successful aging. Creative expression, through creative engagement and creative activity throughout one's life, may occur more frequently as one ages, due to more time available to focus on projects of personal interest and challenge.

\section{Creative Engagement and Creative Activity}

McFadden and Basting [25] believe creative engagement involves any activity that enables an individual to formulate a new idea or product into the world from one's imagination. The primary goals of creative engagement for older persons are freedom of expression and socialization [25]. Creative engagement can occur in a variety of ways; such as, trialing a new recipe, writing a new song, rearranging furniture to one's liking, or selecting an outfit for a special occasion. Creative engagement differs from creative activities, such as dance, music, artwork, etc., due to an absence of structure or pattern and how the individual expresses their original thoughts or feelings [25]. 


\section{Creative Activity and the Agentic Self}

Creative activity, whether through thinking or doing, is the process by which the individual seeks an innovative solution to a problem, opening the individual's mind to new ideas and novel approaches [26]. The creative activity does not occur without risk of failure or disappointment, which challenges one's confidence, competence, and cognitive development. Being able to work through the possible successes or failures associated with the creative process, is what strengthens the creative character and fortitude of the successfully aging individual.

Goff [27] believes creativity occurs throughout the life continuum and can be reinforced or explored at any age, through social and personal activities that foster one's curiosity and willingness for self-transformation. By creating an end-product or service, the older person builds on his or her sense of self-competence, self-efficacy, and self-pride. Herzog and House [28] refer to this process as the emergence of the "agentic self", by which the older individual relies on one's talents and abilities, from creative concept to purposeful product. Self-awareness and self-reliance do not manifest in the tangible end-product alone, but in the creative process itself. This ability to create with a sense of purpose has been shown to influence one's positive self-image and personal success in later life [12].

Creative activities typically involve an element of physicality, as seen in dance, music, poetry, theater and journaling $[29,30]$. Journal writing provides an opportunity for older people to self-reminisce about their lives in a private, non-judgmental manner [30]. Baldwin states (1990), the act of journaling provides the older adult with a visual record of their past life events and encourages a sense of responsibility for one's actions throughout one's life. Journal writing has been found to foster creativity by strengthening spiritual awareness and personal growth $[29,16]$.

Another activity linked with creative empowerment involves therapeutic group work, by which older adults may develop creative abilities through shared experiences, varied viewpoints, and challenges to their perceptions of past life events $[31,32]$. Group members may experience enhanced self-esteem, life satisfaction, improved problem-solving ability, and increased creativity [31,32]. Group work involving the act of reminiscing has been found to be beneficial to the older adult's creative development by fostering positive mental health benefits [31]. Sharing one's life story in later life appears to involve both the right and left cranial hemispheres $[31,21]$. As a result, when the older adult self-reminisces, neural connections in the brain can be developed and strengthened, further fostering creativity through successful aging [16].

\section{Social Roles Associated with Creativity and Successful Aging}

Corbett [16] suggests older adults who are relatively healthy in mind and body can function as role models for younger generations by serving as educators, supporters, and storytellers; bringing to life important life lessons through lived experience. Older adults can serve as informal historians of the family timeline and historians of local and world events of yesteryear. They can advocate for the rights of marginalized populations through policy change and social responsiveness, without fear of being socially ostracized. Older adults can also act as ethical counselors, by their example of living a self-actualizing life. Lastly, older adults can serve as futurists for society, by reminding younger generations of societal past mistakes and forecasting future possibilities.

\section{Physiological Benefits of Creativity}

Typical changes in the brain occur as one ages, including decreased brain size, increased plaque formation, neurofibrillary tangles, and decreased blood flow, often resulting in short-term memory deficits [5]. Research has shown that through cognitive stimulation exercises during group activities, the older adult's brain develops new dendritic (nerve cell) branches, which enhance the transmission of acetylcholine, the neurotransmitter closely involved in memory and intellectual development [31]. Research also suggests that from the fifth to seventh decades of one's life, the length and growth rate of individual dendrites increases in different parts of the brain [33], which may lead to a resurgence of creative expression.

The growing field of educational gerontology looks at programs and activities that foster further intellectual development in the evolving brain of older adults. Educational programs such as Elderhostel, the Osher Lifelong Learning Program, and the University of the Third Age are just a few institutions dedicated to successful life-long learning in older adulthood [16].

Knowledge acquisition through creative purpose also affects older adults on a physiological level. When an older adult is engrossed in a creative activity, the parasympathetic (automatic) nervous system is activated; thus, lowering the individual's heart rate, blood pressure, and respiration rate, resulting in a more relaxing and enriching experience [34]. Creative activities also stimulate the hypothalamus to stabilize hormonal levels and activate the older adult's immune system $[35,36]$. Besides the physiological benefits creativity provides seniors, creative activity also has positive psychological and spiritual benefits for older adults.

\section{Psychological and Spiritual Benefits of Creativity for Older Adults}

Research indicates positive attributes of creative activities for older adults include improved mental clarity, greater adaptability to life's challenges, improved health, and increased insight and spiritual awareness $[37,20,16]$. 
Spiritual connectedness associated with successful aging does not always mean the older adult ascribes to a formalized theology. Many older adults find satisfaction in later life by choosing to participate in spiritually-fulfilling activities, such as attending religious services or volunteering at a food bank, as a way of feeling part of their community. For some adults, tending to their spiritual needs offers personal forgiveness, mental healing, and a sense of readiness for the unknown. Creativity in later life may be beneficial for older adults that have lost loved ones and may find themselves saddened and bored with their altered lifestyle. Corbett [16] views these life-shifting events as an opportunity for the older adult to reinvent themselves through deviation from their daily routine due to their loss. Older adults may try new creative activities, like learning to play an instrument or perfecting a yoga pose, that they may now have the time and interest in mastering. Research involving older adults with self-professed creative ability indicates the importance of creative expression and successful aging.

\section{Study Supporting Creativity and Successful Aging}

In a study by Fisher and Sprecht [11], thirty-six local artists ranging in age from 60-93 were interviewed about their perceptions of creativity in later life. Twenty-four (67\%) of respondents stated creativity involved hands-on application resulting in a tangible product. Other participants (28\%) believed creativity had more to do with cognitive involvement experienced during a creative activity. A reoccurring theme that emerged was the respondents' ability to think outside of themselves; meaning, putting all their efforts into the creative endeavor, without regard to the outside world. Some respondents enjoyed the social aspects of connecting with others and sharing in peer accomplishments as well as their own. Almost fifty percent of the participants stated one benefit of performing a creative activity was the temporary relief of pain they experienced, in addition to greater motivation to follow-through on the creative process [11]. Most respondents believed that creativity required a certain degree of time and personal health. These findings suggest that creativity involves time and self-commitment, positive health status, physical and cognitive creative ability, and a willingness to become fully engrossed in the creative activity. Study results also suggest that creativity is integral to successful aging by promoting healthy expression of one's hopes, fears, successes and perceived failures.

\section{Creativity and Transferability of Skills}

When an older adult experiences multiple successes from creative experiences throughout their life, such a person may also experience positive results in other life domains (areas of expertise), such as fiscal responsiveness, social advocacy, and work-life balance. Schulz \& Heckhausen [10] state transferable skills acquired during the creative process can develop high levels of cognitive, emotional, and social skills in older adults, resulting in healthier and higher functioning successful agers. Other researchers support this ideology by advocating that seniors who have creative competence in one skill can apply the qualities of self-motivation, determination, and confidence in other life sectors. Additionally, these older individuals are more able to cope with the uncertainties associated with life events that arise later in life. Bink and Marsh [38] posit that successfully aging adults use the same cognitive processing skills in their daily lives as they do during creative activities. These operational indicators include "working memory capacity, speed of retrieval, perceptual fluency activation of relevant conceptions and inhibition of irrelevant ones, recall ability, and inspection of memories" (p. 75).

Creative seniors enjoy the uniqueness of their perceptual view of the world and use their innovative skill set when faced with challenges to success in other areas of their life, often with the intention of decreasing feelings of frustration and increasing feelings of personal happiness $[11,20]$. Acquired wisdom through gained knowledge, coupled with lived experience, results in an older adult who has control, balance, and transformative perspective of their life journey [16].

\section{Conclusions}

Creativity influences successful aging by providing an expressive outlet for self-transformation by challenging one's psyche and physical fortitude to go beyond one's expectations. Living a successful life into older adulthood involves creativity manifested by an internal drive to experience life's challenges with optimism and joy. Creativity is influenced by one's cultural upbringing and personal beliefs. Intrinsic motivators of pride and self-efficacy outweigh material wealth and reputation as indicators of success in later life. Spirituality and wisdom developed throughout one's life become more relevant as one ages. Creative expression derives its power and influence from neural pathways of the brain, which can be successfully redirected during the early stages of older adulthood. Fostering creativity through individual or group activities that promote personal choice, self-control, and socialization are requisites to successful aging. Mastering skills of successful living in one facet of the older adult's life can be transferred to other domains through trial-and-error. Successful living in older adulthood requires courage, determination, and personal investment in creating a life one was meant to live, successfully. 


\section{REFERENCES}

[1] World Health Organization (2015). Health statistics and information systems: Definition of an older or elderly person. http://www.who.int/healthinfo/survey/ageingdefnolder/en/

[2] U.S. Census Bureau. (2014). An aging nation: The older population in the United States: Population estimates and projections. U.S. Census Bureau: Current Population Reports. https://www.census.gov/prod/2014pubs/p25-1140.pdf

[3] Centers for Disease Control and Prevention. (2014). Deaths: Leading causes for 2014. National Vital Statistics Reports, 65(5).

https://www.cdc.gov/nchs/data/nvsr/nvsr65/nvsr65_05.pdf

[4] McGuire, L., Strine, T., Okoro, C., Ahluwalia, I., \& Ford, E. (2007). Modifiable characteristics of a healthy lifestyle in U.S. older adults with or without frequent mental distress: 2003 Behavioral Risk Factor Surveillance System. American Journal Geriatric Psychiatry, 15 (9): 754-761.

[5] Tabloski, P. (2006). Gerontological nursing. Upper Saddle River, NJ: Pearson Education.

[6] Schulz, R., \& Heckhausen, J. (1996). A life span model of successful aging. American Psychologist, 51(7), 702-714.

[7] Erikson, E., \& Erikson, J. (1997). The life cycle completed: Extended version. New York, NY: Norton.

[8] Bandura, A. (2001). Social Cognitive Theory: An agentic perspective. Annual Review of Psychology, 52, 1-26.

[9] Erikson, E. (1950). Childhood and society. New York, NY: Norton.

[10] Schulz, R., \& Heckhausen, J. (1996). A life span model of successful aging. American Psychologist, 51(7), 702-714.

[11] Fisher, B., \& Sprecht, D. (1999). Successful aging and creativity in later life. Journal of Aging Studies, 13(4), 457-472.

[12] Edelson, P.J. (1999). Creativity and adult education. New Directions for Adult \& Continuing Education, 81, 3-13.

[13] Duffy, T., Somody, C., \& Clifford, S. (2006). Conversations with my father: Adapting a musical chronology and the emerging life song with older adults. Journal of Creativity in Mental Health, 2(4), 45-63. doi:10.1300/J456v02n04_05

[14] Flood, M. (2006). Exploring the relationships between creativity, depression, and successful aging. Activities, Adaptation \& Aging, 31(1), 55-71. doi:10.1300/J016v31n01-04

[15] Nagalingam, J. (2007). Understanding successful aging: A study of older Indian adults in Singapore. Care Management Journal, 8(1), 18-25.

[16] Corbett, L. (2012). Successful aging: Bringing to life the possibilities and potentials for vibrant aging. Symposium conducted at The Library of Congress, Washington, D.C.

[17] Tsai, K.C. (2013). A review of the inquiry of creativity in older adults in journals. British Journal of Education, 1(2), 20-28.

[18] Featherman, D.L.; Smith, J.; \& Peterson, J.G. (1990). Successful aging in a post-retired society. In Baltes, P.B., Baltes, M.M. (Eds.). Successful aging: Perspectives from the behavioral sciences (pp. 50-93). United Kingdom: Cambridge University Press. doi:10.1017/CBO9780511665684.005

[19] Jeste, D.V., Depp, C.A., \& Vahia, I.V. (2010). Successful cognitive and emotional aging. World Psychiatry, 9(2), 78-84.

[20] Tornstam, L. (2005). Gerotranscendence: A developmental theory of positive aging. New York, NY: Springer.

[21] Flood, M., \& Phillips, K. (2007). Creativity in older adults: A plethora of possibilities. Issues in Mental Health Nursing, 28, 389-411. doi:10.1080/01612840701252956

[22] Csikszentmihalyi, M. (1990). Flow: The psychology of optimal experience. New York, NY: Harper \& Row.

[23] Addams-Price, C. (1998). Creativity and successful aging. New York, NY: Springer.

[24] Fasnacht, P.H. (2003). Creativity: A refinement of the concept for nursing practice. Journal of Advanced Practice, 41(2), 195-202.

[25] McFadden, S., \& Basting, A. (2010). Healthy aging persons and their brains: Promoting resilience through creative engagement. Clinics in Geriatric Medicine, 26(1), 149-161. doi:10.1016/j.cger.2009.11.004

[26] Mariske, M., \& Willis, S. (1998). Creativity and successful aging: Theoretical and empirical approaches. New York, NY: Springer.

[27] Goff, K. (1992). Enhancing creativity in older adults. Journal of Creative Behavior, 26(1), 40-49.

[28] Herzog, A., \& House, J. (1991). Productive activities and aging well. Generations, 15(winter), 49-54.

[29] Baldwin, C. (1990). Life's companion: Journal writing as a spiritual practice. New York, NY: Bantam.

[30] Snyder, M., \& Lindquist, R. (2002).

Complementary/alternative therapies in nursing. New York, NY: Springer.

[31] Cohen, G. (2005). The mature mind: The positive power of the aging brain. New York, NY: Basic.

[32] Hanna, G.P. (2013). The central role of creative aging. The Journal of Art for Life, 4(1), 1-15.

[33] Flood, D., \& Coleman, P. (1990). Chapter 31: Hippocampal plasticity in normal aging and decreased plasticity in Alzheimer's disease. Progress in Brain Research, 83, 435-443.

[34] Samuels, M., \& Lane, M. (1998). Creative healing. San Francisco, CA: Harper Collins.

[35] Lane, M. (2005). Creativity and spirituality in nursing. Holistic Nursing Practice, 19(3), 122-125. 
[36] Mirowsky, J., \& Ross, C. (2007). Creative work and health. Journal of Health and Social Behavior, 48(4), 385-403. doi:10.1177/002214650704800404
[37] Beck, C. (2005). Creative elderhood, what's art got to do with it? http://trace.tennessee.edu/cgi/viewcontent.cgi?article $=1137 \&$ context=utk_nurspubs

[38] Bink, M., \& Marsh, R. (2000). Cognitive regularities in creative activity. Review of General Psychology, 4(1), 59-78. 